\title{
Causes of Non-Prioritization of Infrastructure Projects in the Gaza Strip
}

\author{
Nabil El-Sawalhi", Mohammed Salah Sarhan \\ Civil Engineering Department, the Islamic University of Gaza, Gaza, Palestine \\ Email address: \\ nsawalhi@iugaza.edu.ps(N.El-Sawalhi),moh_serhan86@hotmail.com(M.S. Sarhan) \\ ${ }^{*}$ Corresponding author
}

\section{To cite this article:}

Nabil El-Sawalhi, Mohammed Salah Sarhan. Causes of Non-Prioritization of Infrastructure Projects in the Gaza Strip. Journal of Civil, Construction and Environmental Engineering. Vol. 3, No. 1, 2018, pp. 29-38. doi: 10.11648/j.jccee.20180301.15

Received: February 25, 2018; Accepted: March 10, 2018; Published: April 8, 2018

\begin{abstract}
Infrastructure projects are the backbone of the economy of the developed counties. Gaza Strip is suffering from non-prioritization of infrastructure project implementation. The objective of this paper was to identify the causes of nonprioritization infrastructure projects in the Gaza Strip. This paper considers the key causes of non-prioritizing infrastructure projects in Gaza Strip. Using an empirical questionnaire survey targeting groups consist of 5 ministries, 25 municipalities, 25 NGOs, international agencies and 59 consultancy firms working in Gaza Strip, respondents were invited to rate the level of importance of 52 causes have been finalized to be involved in this study from the literature. Results revealed that the most important causes are related to the project and its location, the surrounded political and economic environment, donors and project's owner. There is no consideration for local needs in the implementation of the infrastructure projects in the Gaza Strip and there are problems in the process of selecting infrastructure projects priorities by owners of these projects. Furthermore, several donors placing limitations on the type of infrastructure that it can support that related to their working area of aids and according to their political directions. Finally, the political and economic situation in Gaza Strip, and imposed borders blockade affects the decision-making process for the selection of the proposed projects. This paper will help the decision makers to consider the important aspects that should be considered when planning to infrastructure projects.
\end{abstract}

Keywords: Infrastructure Projects, Construction, Prioritization, Gaza Strip

\section{Introduction}

Public infrastructure is the network of physical assets created by public investment. These fixed assets include both economic infrastructure (e.g., highways, airports, roads, railways, water and sewer systems, public electric and pipelines, telecommunications) and social infrastructure (e.g., public schools, hospitals, and prisons). The volume of infrastructure is measured using indicators of both access to and quality of the key infrastructure assets, including road, electricity, water, education, and health care institution [1].

Infrastructure is the backbone of economic capacity, but it also impacts directly on humandevelopment, social inclusion, environmental sustainability and so the development of infrastructure is a fundamental concern of both governments and citizens [2]. Many government across the world encounter 'infrastructure financing gaps' due to increasing investment demand for infrastructure with shrinking public

\section{finance [3].}

Public infrastructure in Palestine currently varies from one area to another due to population distribution and limited financial resources. By nature, infrastructure projects require huge capital investment of funds, long range planning, continuous management, commitment of required time, human resources and involve numerous risks. Estimation and management of cost is the major challenge combined with schedule slippages. Above all, stakeholder management is extremely essential and equally difficult.

Infrastructure services, widely deemed- critical to economic development, trade connectivity, social welfare, and public health, are underprovided in many regions and are typically featured in national development plans [4]. It is known that the mandates of infrastructure projects in the Gaza Strip are local government units represented by Ministry of Local Government (MOLG), Municipalities and its Joint Services Councils (JSCs). The majority of infrastructure projects implemented in the Gaza Strip are 
financed by international donor institutions.

Some vital infrastructure investment projects require high initial capital cost and long-term funding and operational management. This requires proper prioritization of needs and efficient infrastructure implementation strategy [5].

In Gaza Strip, the infrastructure projects suffer from lack of planning and management in selecting and implementing relevant priority infrastructure projects. There is neither clear criteria in prioritization of infrastructure projects, nor clear priorities in the implementation phases of infrastructure projects, and there is no clear criteria in selection of appropriate location of projects. The construction priorities are not implemented.

In Gaza Strip municipalities, there is no formal or accountable decision making approach for prioritization of infrastructure projects. The services provided by such projects are severely affected. The lack of management of priorities leads to negatively effects the quality of the projects. Most of the infrastructure projects suffer from rework, increased costs for operating and maintenance and bad maintenance for infrastructure projects and wasting of financial resources through the bad planning. This research is going to identify the causes of non-prioritization the infrastructure projects in the Gaza Strip.

\section{Literature Review}

\subsection{Infrastructure Project Stockholders}

The number of stakeholders involved or interested in the project can dramatically increase the complexity and uncertainty of the situation. Each stakeholder usually has different interests and priorities that can place them in conflict or disagreements with the project [6].

Project stakeholders can be divided into internal and external. Internal stakeholders being those directly involved in an organization's decision-making process (e.g. owners, customers, suppliers, employees). External stakeholders being those affected by the organization's activities in a significant way (e.g. neighbors, local community, general public, local authorities) [7]. External stakeholders are those individuals and organizations that have no formal contractual relationship to the project but can have a strong interest in what is going on regarding the project [8]. In construction, there has traditionally been a strong emphasis on the internal party's relationships such as procurement and site management, while the external parties relationships to some extent have been considered a task for public officials via the rules and legislation that concern facility development [7]. The examples of construction project stakeholders [9] are Client, Consultant, Contractor /subcontractors, Funding body/Donor (i.e. United Nations (UN), World Bank (WB)), International non-governmental organizations /Nongovernmental organizations (acted as the mediator of the funding body and the government), Government, Beneficiary/End User, General public, and Local landowners/ neighborhood. The decision players in Gaza Strip are: a. The decision makers: municipality mayors or councilors, Coastal Municipalities Water Utility (CMWU), heads of departments and Ministry of Local Government representatives (head of the project department and staff).

b. The stakeholder players: including communities, funding agencies, other ministries, other governmental parties (e.g. Environmental Quality Agency "EQA", Palestinian Water Authority "PWA") and relevant local NGOs.

Other parties can be classified according to their roles. The funding agencies may play more important role as a decision maker in some projects [10].

\subsection{Infrastructure Situation in Palestine}

Real gross domestic product (GDP) growth extremely unstable and determined by political events and donor support, which are both unpredictable and outside the control of the Palestinian National Authority [11].

The Gaza Strip is facing a massive deficit in infrastructure, including energy, water, waste, communications and transport systems, which have direct impact on the humanitarian situation and the provision of services, and are key enablers of trade and growth. It is therefore critical that the infrastructure deficit be addressed in a comprehensive and well planned manner with consideration for the long term. The Palestinian Government needs to move forward on structural and approach reforms in the planning and decision making for infrastructure investments if it is to tackle the major infrastructure deficit [12].

Investment in infrastructure and the local economy can drastically improve living conditions in the Gaza Strip. While, donors and civil society actors continue to highlight the plight of the Gaza population, funding shortages and lack of viable political solutions has caused fatigue among the international community, especially concerning the Gaza Strip. This has resulted in the serious neglect of key projects including the reconstruction of necessary infrastructure like water, waste and power facilities [13].

Construction projects located in the Gaza Strip, Palestine suffer from many problems and complex issues. Consequently it is faced with the significant problems of high cost of project delivery, bad financial performance and inability to deliver value to customers on time [14].

The current situation of the infrastructure in Palestine, the reasons that have had a significant role in the Retreat of infrastructure as follows:

1. Lack of long-term strategies for the development of infrastructure preparations.

2. Lack of coordination, follow-up and supervision among stakeholders.

3. Total dependence on sources of donor countries to funding infrastructure projects.

4. The complexities of the regulations and the laws that limit funding.

5. Incompatibility of the funding required timing with implementation plans.

6. No flexibility in capitalization of returns of 
infrastructure services.

7. Limited effective participation of the private sector in the establishing and operation of infrastructure services.

8. The lack of an integrated, unified and updated database for specialists and decision makers.

9. The weakness of the concern and spending on infrastructure projects by the National Authority and the competent Agencies.

10. The existence of pressure on infrastructure led to an increase of environmental deterioration.

11. The weakness of level of services, growth and achieve balanced and sustainable development

12. Limited standards and conditions that determine the paths the development of infrastructure [16].

\subsection{Funding Methodology for Infrastructure Projects in the Gaza Strip}

In Palestine most of the infrastructure projects are funded by external donor. The donations are granted by several consulates of donor countries or through their representatives in Palestine. Other type of funds are granted by international agencies working in Palestine such as; World Bank, UNRWA, United Nations Development Program (UNDP), Community Housing Foundation (CHF), the Department of International Development (DFID), Save the Children (SC), Japanese International Cooperation Agency (JICA), Islamic Development Bank, USAID, and others. The implementing agencies of infrastructure projects are mostly, the Ministry of Local Government, municipalities, the Palestinian Economic Council for Development and Reconstruction (PECDAR). Other infrastructure projects are implemented according to the sector by the Ministry of Public Works and Housing, the Ministry of Natural resources and Energy, the Ministry of Communications, etc. The UNRWA implemented projects in camps.

The international non-governmental organization (INGO's)/non-governmental organization (NGO's) acted as the mediator for the donor, and these implemented agency takes the responsibilities of managing the construction project, and they hired management team to take care with these responsibilities. The management team always faces a lot of challenges one of them how to manage project stakeholder, since the list of these stakeholder contain a large number of stakeholders with different goals. The construction industry worldwide has a poor record of stakeholder management during the past decades, and the construction industry in the Gaza Strip is not an exceptional case [7].

Donor funding played an important role in the development of the Palestinian NGO infrastructure. Since 1967, donor assistance created a reliable revenue stream, built internal capacity and transferred technical know-how and development experience to NGOs in all sectors of Palestinian society. However, the relationship of Palestinian NGOs and the donor community is not without negative aspects. Donor aid is often accompanied by specific, and sometimes conflicting, political agendas. Lack of internal organization and clearly established sets of priorities within the NGO community forced many civil society associations to accept without challenge the will of donor groups [17].

The heightened state of dependency weakened the ability of Palestinian NGOs move decisively in the direction of sustainable development, and resulted in the wasting of financial resources, duplication of projects, diminished quality of services, and a subjugation of the NGO leadership and vision to the donor community. In addition, donors unintentionally pitted NGOs against one another in an unhealthy competition for funding. NGOs tailored their programs to align with the stated objectives of donor initiatives in order to secure resources. Indeed, one of the conclusions of the Palestine Human Development Report is that: "There is a lack of clearly established and articulated Palestinian priorities within a comprehensive Palestinian development vision [17].

\subsection{Strategic Concept for Prioritization Infrastructure Projects}

There are growing demands, especially in countries of limited resources to provide more services with fewer resources. Governments have been responsible for managing urban infrastructure in many countries worldwide. At the moment, there is a growing belief that the provision of infrastructure needs to be conceived and run jointly with the private sector as a service industry responding to customer demand. Some vital infrastructure investment projects require high initial capital cost and long-term funding and operational management. This requires proper prioritization of needs and efficient infrastructure implementation strategy, which takes into consideration the multiple-criteria nature of the problem with its conflicting objectives [5].

Marcelo et al.[18] identified four primary decision support principles that suggest how prioritization should be done. These are accuracy, practicality, political feasibility, and suitability. The first, accuracy, demands that methods of prioritization be sufficiently precise to afford meaningful comparisons amongst projects, suggests that thresholds of 'correctness' are required to ensure that the logic of evidence is attained and reliable. The second two conditions practicality and political feasibility - are quite clear-cut and underpinned by the common thread of feasibility. The first, practicality, attends to the administrative feasibility of the prioritization process and deals with the institutional capacity, the cost and time limits of decision-making imposed on analysts, consultants, and decision-makers, and the availability and quality of information upon which decisions must be based. The second principle, political feasibility, accepts that there is a balance to be struck between technical objectivity and political representation and accountability.

Lastly, the principle of suitability demands that the criteria selected for decision-making be appropriate to judge the relative desirability of projects. The suitability of decision criteria is dependent on policy goals, general norms of governance, and the availability of information associated 
with a potential criterion.

Mainly, resources limitation requires the use of a procedure to rank and prioritize the set of proposed infrastructure projects [19]. The choice of what infrastructure to be selected has implications for public sector discretionary control, value-for-money and affordability. In many countries, however, the choice of the project is often based on habit and lacks specific criteria for traditional infrastructure projects [20]. In addition, evidence should be provided that the project's rationale responds to a priority for the territory [21].

\section{Research Method}

This study was designed to determine the reasons for nonprioritization of the infrastructure projects in Gaza Strip. The questionnaire is used as the main approach to collect the data and perspectives of the respondents. The research population involved governmental ministry, municipality, $\mathrm{NGO}^{\text {ee }}$, international agencies and consultant firms who have the greatest influence and the main responsibility of infrastructure projects proposals and selection.

The targeted population groups consist of 5 ministries, 25 municipalities, $25 \mathrm{NGOs,} \mathrm{international} \mathrm{agencies} \mathrm{and} 59$ consultancy firms working in Gaza Strip. The samples of this study are individuals have been selected randomly from proposed population groups. A statistical calculation approach been used to determine the required sample size from the whole population that involved 114 institutions.

Several face-to-facemeetings and discussions were conducted with six experts from different academic and technical fields to fine tune the preliminary lists of the collected variables and to validate the results of the literature review. 25 copies of the filled questionnaires have been selected randomly to perform pilot testing. These copies were analyzed to test the validity and reliability of the study questionnaire.

\section{Data Analysis and Discussion}

\subsection{Respondents Profile}

This section presents brief background information of the survey respondents' data as shown in Table 1. Basic factual data was collected relating to the questionnaires respondents which should be considered when interpreting the findings. Analysis of the returned questionnaire showed that $45.3 \%$ of respondents work in municipalities. Clearly, this result increases the credibility and reliability of the results because local municipalities form the backbone of public administration in the Palestinian Territory. $18.6 \%$ of the respondents work in consulting firms that have a prominent role and their contribution may affect relationships and the quality and progress of project. Further, 39.5\% of respondents are engineering staff which include office engineers and site engineers. In addition, the respondents have good academic background and satisfactory knowledge for providing sufficient details and inputs for the outcome of this research work. Therefore, the opinions obtained through this survey tend to be more accurate and representative.

Table 1. Respondent's profile.

\begin{tabular}{|c|c|c|c|}
\hline Information about respondents & Categories & Frequency & Percentage $\%$ \\
\hline \multirow{4}{*}{ Respondent's organization work classification } & Governmental agencies (ministries) & 19 & 21 \\
\hline & Municipality & 39 & 45.3 \\
\hline & UN, NGO's \& INGO's agencies & 12 & 14 \\
\hline & Consultant firms & 16 & 18.6 \\
\hline \multirow{3}{*}{ Respondent's position in the organization } & Organization director & 8 & 9.3 \\
\hline & Head of department & 24 & 27.9 \\
\hline & Projects manager & 20 & 23.3 \\
\hline \multirow{4}{*}{ Respondent's years of experience } & Less than 5 years & 6 & 7 \\
\hline & From 5 to less than 10 years & 21 & 24.4 \\
\hline & From 10 to less than 15 years & 29 & 33.7 \\
\hline & More than 15 years & 30 & 34.9 \\
\hline
\end{tabular}

\subsection{Causes Affecting Non-Prioritization the Infrastructure Projects}

Although the economic and social value of the infrastructure projects, there are many factors can play a major role in setting priorities for a project to be selected. From literature review, in depth study and experts' suggestions about 52 causes have been finalized to be involved in this study. In addition, these causes have been grouped in 7 groups according to its nature and source.

\subsubsection{Donors - Related Causes}

Donors have an ongoing commitment to achieving value for the projects and programs which it supports. Table 2 shows the mean, standard deviation (SD), t-test results and its ranking hierarchy on the basis of their influence in nonprioritization of the infrastructure projects in Gaza Strip. One-sample t-test has been performed to examine whether the fifteen causes identified in this study can influence prioritization of the infrastructure projects in Gaza Strip. It can be shown from Table 2 that ten causes from the listed causes have $p$-value less than the significance level of (0.05) and positive $t$-value larger than the critical t-value (1.99). In addition, these 10 causes have positive t-value which reflects that their means are larger than the hypnotized mean value (larger than 3) which indicates that the respondents agreed 
about the influence of these causes.

The factor "The size and objectives of the fund affect the types of the proposed projects", is ranked as the first cause in the donor related causes group with $(\mathrm{SD}=0.75$ and $\mathrm{p}$ value $=0.00)$. Clearly, this mean that project site, objectives, scope and desired benefits must all be addressed when planning infrastructure projects. Funds must be clearly designated and committed to the project so as to ensure successful implementation of activities without the possibility of stalling and subsequent abandonment [22].

"Funding sources control the selection of infrastructure projects" is in the second position. In fact, with constrained government budgets and the immense need for infrastructure, governments must look to release alternatives sources of financing [23]. It is well known that health and education projects for major donors remain as a top priority for constructing infrastructure projects to ensure greater access to these two services. Funding rules and regulations for donors differ from the recipient countries and in most cases the donor rules prevail [22]. In addition, the project owner must abide by all rules and regulations to get fund.

Moreover, the factor "Allocated fund from donors less than the project budget which leads to cancel some of project stages" is ranked in the third position. To some extent, there may be a gap between the budget approval and the actual committed budget, meaning further project funds had to be mobilized to fill the gap between approval and commitment. Clearly, sometimes several projects may be ignored or ended at the initial stages only, because there is not enough fund [24].

Table 2. Analysis results of donors' related causes.

\begin{tabular}{|c|c|c|c|c|c|}
\hline Donors' related causes & Mean & SD & t-value & P-value (2-tailed) & Rank \\
\hline The size and objectives of the fund affect the types of the proposed projects & 4.26 & 0.75 & 15.44 & 0.00 & 1 \\
\hline Funding sources control the selection of infrastructure projects & 4.08 & 1.01 & 9.95 & 0.00 & 2 \\
\hline $\begin{array}{l}\text { Allocated fund from donors less than the project budget which leads to cancel some } \\
\text { of project stages }\end{array}$ & 3.92 & 1.05 & 8.08 & 0.00 & 3 \\
\hline $\begin{array}{l}\text { Donors are targeting specific sectors and putting several restrictions on certain types } \\
\text { of projects so that the prioritization influenced }\end{array}$ & 3.85 & 0.96 & 8.16 & 0.00 & 4 \\
\hline Donor's opinion is considered as a top priority & 3.72 & 1.09 & 6.12 & 0.00 & 5 \\
\hline $\begin{array}{l}\text { Donors' intervention in partitioning the projects stages lead to execute some of } \\
\text { projects and suspend others }\end{array}$ & 3.71 & 1.16 & 5.69 & 0.00 & 6 \\
\hline $\begin{array}{l}\text { Donors focusing on funding relief and emergency projects on account funding of } \\
\text { long-term infrastructure projects }\end{array}$ & 3.67 & 1.19 & 5.24 & 0.00 & 7 \\
\hline Donors' unwillingness to funding projects with expected obstacles & 3.65 & 1.03 & 5.88 & 0.00 & 8 \\
\hline Donors' intervention in the selection of infrastructure projects & 3.47 & 1.28 & 3.37 & 0.00 & 9 \\
\hline Contradiction in the projects selection criteria between the project owner and donor & 3.37 & 0.92 & 3.75 & 0.00 & 10 \\
\hline
\end{tabular}

SD: Standard Deviation.

\section{Causes Related to Communication Means with Donors}

Table 3 shows that "Incorrect reflection about Gaza Strip real situation by donor agent "is the highest ranked factor. Undoubtedly, accurate information about local needs is vital components to support selecting the most important project. Sartori et al. [21] reported that, the possibility of getting financing for project often relies on the assessment's accuracy ofthe macro-economic and social conditions of the country in which the project will be implemented. Too often, it seems that donors' agents didn't asses and provide adequate information about the long-term needs and situation in Gaza Strip. This left many issues unsolved during the project selection \& designing phase [22] reported that the existence of intermediary institutions between donors and project owner has led to delays compounded by protocols or inadequacies between funding agency and the owners.

The respondents also ranked "Communication weakness between project owner and donor" with in the second position. This result can be attributed to rare discussion between the donor and the owner about the proposed funds that the donor intended to provide and no discussion if the owner has different priorities of proposed funds. Factually, project success is strongly linked to communication and cooperation between stakeholders. Effective infrastructure projects require substantial coordination and communication between project's participants to bridge information, policy or fiscal gaps that may occur [2]. Roos et al. [24] recommended owners to have an overview of existing funding sources, support for finding them, and better coordination with them.

Table 3. Analysis results of the causes related to communication means with donors.

\begin{tabular}{|c|c|c|c|c|c|}
\hline Causes related to communication means with donors & Mean & SD & t-value & P-value (2-tailed) & Rank \\
\hline Incorrect reflection about Gaza Strip real situation by donor agent & 3.49 & 1.22 & 3.73 & 0.00 & 1 \\
\hline Communication weakness between project owner and donor & 3.45 & 1.09 & 3.85 & 0.00 & 2 \\
\hline $\begin{array}{l}\text { Direct communication mechanisms between project owners and donors are not exist and } \\
\text { without it is done with mediators, generally }\end{array}$ & 3.29 & 1.27 & 2.12 & 0.04 & 3 \\
\hline $\begin{array}{l}\text { NGO's and international donor agents in Palestinian territories playing negative role in } \\
\text { priority ranking }\end{array}$ & 3.28 & 1.22 & 2.11 & 0.04 & 4 \\
\hline
\end{tabular}




\subsubsection{Causes Related to Consultants}

The first factor is "Consultant selection on financial base not on professional base" with. Doing so necessarily biases the consultant selection results because, in the decision process, it implicitly assigns a much larger weight to the consultant financial capabilities than to their professional capabilities. Runde et al. [25] demonstrated that both technical and financial assistance, is most critically needed for infrastructure projects to develop a well-planned infrastructure projects. So that, there is no doubt that governments and officials should complement their in-house skills with external skills to provide specialist knowledge and insight [23]. However, Rathbone \& Redrup [23] reported that emerging markets often lack advisory capability (legal, technical and financial) to address the many risks inherent in large scale infrastructure. The second cause is "Delays and slow decision making by donors' consultant". Clearly, most projects are not completed on time and implementation activities are punctuated with occasional stoppages of project works hence delayed benefits to intended citizens [22]. In addition, updating data and filling the gaps is costly and time consuming and demands a significant allocation of resources [26].

Table 4. Causes related to consultants.

\begin{tabular}{|c|c|c|c|c|c|}
\hline Causes related to consultants & Mean & SD & t-value & P-value (2-tailed) & Rank \\
\hline Consultant selection on financial base not on professional base & 3.58 & 1.21 & 4.45 & 0.00 & 1 \\
\hline Delays and slow decision making by donors' consultant & 3.51 & 1.06 & 4.48 & 0.00 & 2 \\
\hline $\begin{array}{l}\text { The weakness of the skill, qualifications and Lack of experience in planning field of the } \\
\text { donor consultant staff }\end{array}$ & 3.47 & 1.25 & 3.44 & 0.00 & 3 \\
\hline Poor communication between consultant team and the owner & 3.29 & 1.21 & 2.23 & 0.03 & 4 \\
\hline $\begin{array}{l}\text { Lack of commitment of the consultant team in designing according to the project owner } \\
\text { specifications and standards }\end{array}$ & 3.24 & 1.18 & 2.06 & 0.04 & 5 \\
\hline
\end{tabular}

\section{Causes related to project's owner}

Table 5 shows that the first cause affecting non-prioritizing infrastructure projects locally is "Owners interest only in getting funding for the projects without considering the priorities". Because there has been less money available from traditional funding sources to meet the local needs, funding agencies have been reluctant to provide funding in many types of new infrastructure projects. Hence, local owners don't test whether the proposed project as specified will be economically viable and whether it will generate good value for the community. Roos et al. [24] concluded that that there is a strong need for capacitating the public sector project owner for successful projects selection and implementation. Owners' policies especially, government determine how the fund will be used in addition to which sectors of the economy to prioritize funding [22].

In the second position is "Owners' organizations are forced to change their policies and priorities in order to get the funding". This result comes from the local organizations considerations related to the political interests of donors, which considered as more important and these organizations change their projects' priorities not determining whether the fund contribute to the achievement of the needs or development of Palestinians. In many times, to be accepted by funding agencies, proposed infrastructure projects must comply with all donors' requirements and policies. The following in importance is "Some projects are selected according to the owners' organization senior management desires". Senior management is the only part that has the decision to choose project priorities without the participation of any employees of the owner's organization. Lack of senior management confidence in the abilities of the employees leads to neglect in the decision-making process. In general, financial profitability and economic value are probably the most common selection decision considerations. The instability of owners' institutions in management system in decision making will lead to frequent change in the regulatory framework that will increase the sense of risk and arbitrary decisions for project developers [2].

The factor "Owners' organization refuse to get finance for sectors or projects imposed from donors" comes in the last position of the causes involved in the owner's related group. Often, some donors finance specific sectors of infrastructure projects and refuse financing other sectors. Generally, this is one of good practices between donor agencies which aimed mainly at preventing unnecessary duplication of work types for partner agencies.

Table 5. Causes related to project's owner.

\begin{tabular}{|c|c|c|c|c|c|}
\hline Causes related to project's owner & Mean & SD & t-value & P-value (2-tailed) & Rank \\
\hline Owners interest only in getting funding for the projects without considering the priorities & 3.78 & 1.17 & 6.16 & 0.00 & 1 \\
\hline $\begin{array}{l}\text { Owners' organizations are forced to change their policies and priorities in order to get the } \\
\text { funding }\end{array}$ & 3.77 & 1.09 & 6.52 & 0.00 & 2 \\
\hline Large projects proposals aren't ready in the form of stages to fragment the funding & 3.69 & 1.12 & 5.68 & 0.00 & 4 \\
\hline $\begin{array}{l}\text { Owners' organizations take the donor policy in account in the selection of proposed projects } \\
\text { which influence their priorities ranking }\end{array}$ & 3.69 & 1.03 & 6.16 & 0.00 & 5 \\
\hline $\begin{array}{l}\text { Owners' organizations senior management have alone the authority for the decision-making } \\
\text { with regard to determining the list of proposed projects }\end{array}$ & 3.59 & 1.13 & 4.86 & 0.00 & 7 \\
\hline
\end{tabular}




\begin{tabular}{|c|c|c|c|c|c|}
\hline Causes related to project's owner & Mean & SD & t-value & P-value (2-tailed) & Rank \\
\hline $\begin{array}{l}\text { Unclear objectives and vision in the owner organization to persuade donors in funding } \\
\text { projects according to their priorities }\end{array}$ & 3.53 & 1.21 & 4.08 & 0.00 & 8 \\
\hline $\begin{array}{l}\text { Owners don't hire experts from outside their organizations to participate in planning process } \\
\text { to choose the priority projects }\end{array}$ & 3.53 & 1.20 & 4.15 & 0.00 & 9 \\
\hline $\begin{array}{l}\text { Specialists and related parties in the owner organization aren't involved in plans development } \\
\text { and priorities setting }\end{array}$ & 3.51 & 1.15 & 4.14 & 0.00 & 10 \\
\hline Poor qualifications and lack of experience of the owner's team & 3.50 & 1.25 & 3.70 & 0.00 & 11 \\
\hline
\end{tabular}

\subsubsection{Causes Related to Project Design and Planning}

Table 6shows the top factor is "Inaccurate cost estimation of the proposed projects" with. It is well known that, consistent estimates of projects costs are a pre-requisite for developing a sound menu of priorities and financial options to close the infrastructure gap. Many projects are ignored by owners or even donors because of the illogical cost estimates associated with them. On the other hand, many important projects lose its priority because of their imprecise cost estimates. Liesiö, Mild \& Salo [27] concluded that the need to consider the costs and multiple benefits of investment options and the uncertainty that surrounds these estimates makes systematic and efficient resource allocation a complex problem.
"Planners don't apply modern technical techniques in identifying the projects priority" comes in the second position. In fact, creation of durable and high quality infrastructure is a prerequisite for rapid economic development and requires sustained investment well supported by technological innovations, skilled workforces and excellent project managements. Locally, many infrastructure projects are selected by unorganized manner and do not rely on specific tools. Several previous studies have concluded scientific and technical techniques related to studying the best tools to determine the priorities of the infrastructure projects. Accurately, local key players aren't provided with an effective, transparent tool to be used in the project selection process [28].

Table 6. Causes related to project design and planning.

\begin{tabular}{|c|c|c|c|c|c|}
\hline Causes related to project design and planning & Mean & SD & t-value & P-value (2-tailed) & Rank \\
\hline Inaccurate cost estimation of the proposed projects & 3.41 & 1.16 & 3.25 & 0.00 & 1 \\
\hline Planners don't apply modern technical techniques in identifying the projects priority & 3.38 & 1.06 & 3.34 & 0.00 & 2 \\
\hline Improper preparation of the project's feasibility study & 3.36 & 1.19 & 2.82 & 0.01 & 3 \\
\hline $\begin{array}{l}\text { Frequent errors and problems in proposed project design leads to rejecting the project from } \\
\text { the donors }\end{array}$ & 3.26 & 1.23 & 1.93 & 0.06 & 4 \\
\hline Improper and unclear planning and design for the project & 3.19 & 1.02 & 2.42 & 0.04 & 5 \\
\hline
\end{tabular}

\subsubsection{Causes Related to the Project \& its Location}

In Table 7 below, it is observed that most effective cause is "Shortages of materials and equipment needed for project". Shortage of materials and equipment's addressing a particular problem that is encountered with infrastructure projects. Actually, the purpose when proposing any infrastructure project is to implement it on the ground and its implementation requires the necessary materials and equipment. Therefore, it is illogical to prioritize a project that we cannot provide the necessary materials and equipment for its implementation. Keng'ara [22] demonstrated that for a project to undertake its activities, assets such as machinery, equipment must be provided. "The location of the project has the impact on its selection within priorities (besides military sites)" was located in the second position. The location of the project is one of the main factors in the selection of infrastructure projects and it affects the type of the proposed projects. Many of the border areas in the Gaza Strip prevent the implementation of vital projects and at the same time some projects are selected to be in the border areas such as wastewater projects and sewage treatment plants. To keep the project alive, many infrastructure projects are not carried out near to military sites. Some projects that cause noise may be difficult to be implemented in crowded areas in Gaza Strip. The selection of a project site for any infrastructure project should reflect the particular needs of the population that this project will serve.

"The size of works related to the project have the impact on its selection within priorities" was the least important. Despite the delayed location of this variable, it clearly affects the non-prioritization of infrastructure projects in Gaza Strip.

Table 7. Analysis results of the related to the project \& its location.

\begin{tabular}{|c|c|c|c|c|c|}
\hline Causes related to the project $\&$ its location & Mean & SD & t-value & P-value (2-tailed) & Rank \\
\hline Shortages of the materials and equipment needed for the project & 3.91 & 1.11 & 7.56 & 0.00 & 1 \\
\hline $\begin{array}{l}\text { The location of the project has the impact on its selection within priorities (borders areas - } \\
\text { near military sites ) }\end{array}$ & 3.86 & 1.00 & 8.01 & 0.00 & 2 \\
\hline The project's cost and its operation and maintenance difficulties & 3.58 & 1.07 & 5.05 & 0.00 & 4 \\
\hline $\begin{array}{l}\text { The size of the expected difficulties and drawbacks when implementing the proposed project } \\
\text { prevent its selection in the priorities list }\end{array}$ & 3.55 & 1.07 & 4.74 & 0.00 & 5 \\
\hline The size of works related to the project have the impact on its selection within priorities & 3.36 & 1.00 & 3.33 & 0.00 & 7 \\
\hline
\end{tabular}




\subsubsection{Causes Related to the Surrounded Environment}

Table 8 shows that the survey respondents agreed that the most effective cause in the surrounded environment causes group is "Funding from donors affected by the change of the regime in Gaza Strip". It is well known that the first step of any project appraisal includes clear description about the social, economic, political and institutional context in which the project will be implemented [21]. Lane \& Bulir [29] found that the contribution of a fund to growth depends very much on the country' policies in place and major donors focuses greater attention on the policies associated with donor country policies. In fact, whereas some infrastructure projects are proposed to solve local infrastructure problems, and mainly to boost development and economic growth in Gaza Strip, still major projects have resulted primarily from local political situation. Jerve \& Niss [30] argued that the political commitment of successive governments would ensure a high priority in fund allocation over time to sectors and regions where a specific donor assisted infrastructure project is placed.
"The real political and economic situation in Gaza Strip, and imposed blockade affects the decision-making process for the selection of the proposed projects" with $(\mathrm{SD}=0.98$ and pvalue $=0.00$ ) comes in the second position. Runde et al.[25] highlighted that major international donors frequently "tie" their aid to regulatory reforms, good governance, human rights, and other issues that sovereign nations may find intrusive. Eventually, Palestinian situation is linked with high political and commercial risks and these circumstances including economic and political situations should be taken into account to help in determining what is the most acceptable type of the infrastructure projects to be funded [31].

"Local community committees affect the selection of a list for proposed projects" comes in the last position of the proposed nine causes related to the surrounded environment. While infrastructure projects economic development impacts are important to stakeholders and decision-makers one cannot ignore the fundamental fact that the rationale for infrastructure projects, first and foremost, is the fulfillment of the local needs.

Table 8. Causes related to surrounded environment.

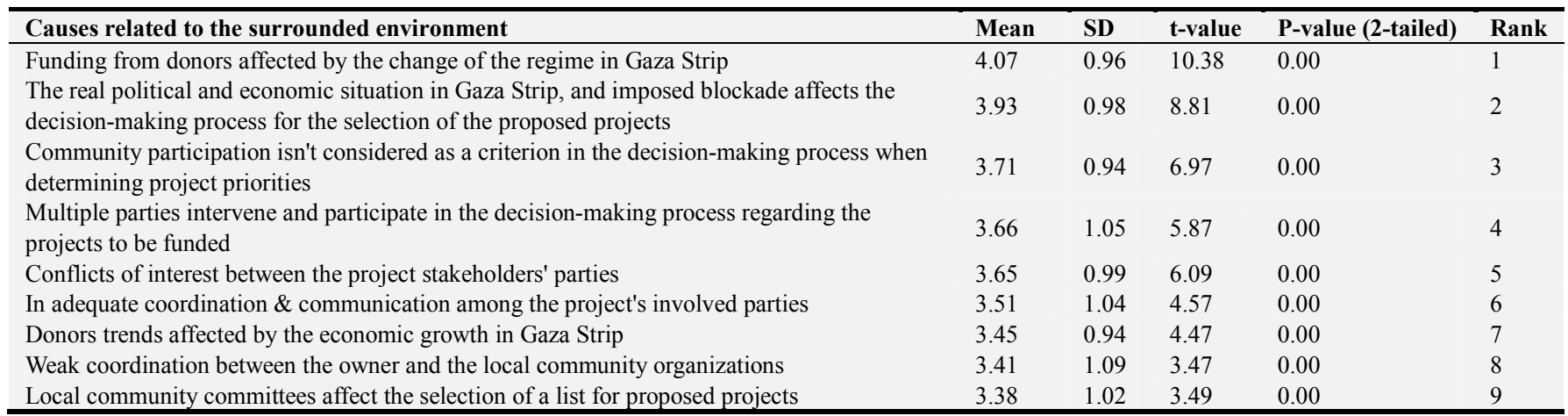

\subsubsection{All Groups of Causes for Non-Prioritization the Infrastructure Projects in Gaza Strip}

Overall, the analysis of the influence of all groups of the causes affecting non-prioritization of the infrastructure projects in Gaza Strip are shown in Table 9 which indicates that the influence of the causes related the surrounded environment is a major concern in influencing nonprioritization of the infrastructure projects in Gaza Strip, while causes related to project design and planning are considered to have a moderate or less influence. Comprehensive knowledge about the project surrounded environment helps in sound planning which in-turn helps in clarifying the scope and developing a thorough understanding and priorities. Also, high influence on nonprioritization caused by the project $\&$ its location are perceived. Furthermore, the fact that the standard deviations for all groups less than 1.0 indicates that there is little variability in the data and consistency in agreement among the respondents about these groups [32].

The previous results reflect the respondents' view of the existence of obstacles to prioritizing the infrastructure projects in the Gaza Strip, which need to take large-scale measures to avoid these barriers and to implement projects in the best way according to the local economic, societal and political needs.

Table 9. Analysis results of all causes for non-prioritization the infrastructure projects.

\begin{tabular}{|c|c|c|c|c|c|}
\hline Causes for non-prioritization of the infrastructure projects in Gaza Strip. & Mean & SD & t-value & P-value (2-tailed) & Rank \\
\hline Causes related to the surrounded environment & 3.64 & 0.62 & 9.63 & 0.00 & 1 \\
\hline Causes related to the project $\&$ its location & 3.62 & 0.72 & 8.00 & 0.00 & 2 \\
\hline Donors related causes & 3.55 & 0.58 & 8.76 & 0.00 & 3 \\
\hline Causes related to project owner (client) & 3.46 & 0.70 & 6.10 & 0.00 & 4 \\
\hline Causes related to communication means with donors & 3.38 & 0.88 & 4.00 & 0.00 & 5 \\
\hline Causes related to consultants & 3.35 & 0.94 & 3.45 & 0.00 & 6 \\
\hline
\end{tabular}




\section{Conclusion}

This study aims at assessing the causes that imped the prioritization infrastructure projects. The technical and institutional complexities of the infrastructure sector require an integrated approach to project selection and planning. Developing and maintaining infrastructure to promote economic development and enable access to life improving services is a key challenge for the Palestinian Territories.

It can be concluded that there is no consideration for local needs in the implementation of the infrastructure projects in the Gaza Strip. There are problems in the process of selecting infrastructure projects priorities by owners. The results indicated that community participation hasn't introduced and there are no comprehensive analyses studies to specify local needs. There is a shortage in the owners' technical, financial and institutional capacity and skills.

Most of respondents endorsed the donors affects in the prioritization process of selecting infrastructure projects. Major infrastructure projects are financed by other countries or several international funding agencies working in Palestine. In most times, these donors allocate and distribute the funds and only finalize the selection criteria of the targeted projects.

There are more critical factors that cause misleading in prioritization of the infrastructure projects in Gaza Strip. These factors are related to communication means with donors, project's owner, the project design and planning, the project $\&$ its location and the surrounded political and economic environment.

The most important factors that affecting on prioritization process of selecting infrastructure projects are the size, sources, objectives of the fund. In addition, donors are targeting specific sectors and setting several restrictions on certain types of projects so that the prioritization influenced. Shortages of materials and equipment needed for project and the location of the project has the impact on its selection within priorities. Finally, owners interest only in getting funding for the projects without considering the priorities in order.

The results presented in this study will help beneficiaries, public decision-makers and independent reviewers to better understand what information (causes) is required to avoid miss priority of proposed projects.

\section{References}

[1] International Monetary Fund, \& van Eden, H. (2015). Making public investment more efficient. Public Financial Management Blog, 2015-2007.

[2] OECD, (Organization for Economic Co-operation and Development) (2015). Towards A framework for the Governance of Infrastructure. Retrieved from Ankara, Turkey.

[3] Secchi, C., Bodewig, K., Grosch, M., Peijs, K., Cox, P., Balazs, P., \&Brinkhorst, L. (2015). The work plans of the 11 European
Coordinators for the TEN T have been finalized, establishing the basis for action until 2030. Brussels, Belgium: The information publishing European Commission, Directorate General for Mobility and Transport. Retrieved from http://ec.europa.eu/transport/themes/infrastructure/news/2015, 5, 28.

[4] Nigim, K., Hipel, K., \& Smith, G. (2006). An effective multiple criteria approach to infrastructure reconstruction in devastated countries. Journal of Systems Science and Systems Engineering, 15 (2), 232-246.

[5] Ziara, M., Nigim, K., Enshassi, A., \&Ayyub, B. M. (2002). Strategic implementation of infrastructure priority projects: case study in Palestine. Journal of infrastructure systems, 8 (1), 2-11.

[6] Karlsen, J. T. (2008). Forming relationships with stakeholders in engineering projects. European Journal of Industrial Engineering, 2 (1), 35-49.

[7] Hammad, S. (2013). Investigating the stakeholder management in construction projects in the Gaza Strip. (Master Thesis), Islamic University, Gaza.

[8] Elmahroug, M. H., Tutesigensi, A., \& Brookes, N. J. (2014). Integrating external stakeholder identification and project initiation in civil engineering infrastructure projects. Paper presented at the Proceedings 30th Annual ARCOM Conference.

[9] Siriwardena, N., Haigh, R., \& Ingirige, B. (2010). Managing stakeholder expectations of post-disaster housing reconstruction projects in Sri Lanka. University of Salford, UK, Issue Published paper.

[10] Taha, S. (2004). A decision making approach for prioritization of municipal infrastructure projects. Islamic University of Gaza.

[11] UNCTAD, (United Nations Conference on Trade and Development) (2015). Report on UNCTAD assistance to the Palestinian people: developments in the economy of the Occupied Palestinian Territory. Geneva: United Nations.

[12] UNSCO, (United Nations Special Coordinator) (2016). Report to the Ad Hoc Liaison Committee Retrieved from New York, 18-19 September 2016.

[13] UNDP, (United Nations Development Program) (2016). Building Resilience in Gaza: Challenges and Opportunities. Paper presented at the Palestine Resilience Conference, Amman, Jordan. 24-25 November 2016.

[14] Enshassi, A., Mohamed, S., \&Abushaban, S. (2009). Factors affecting the performance of construction projects in the Gaza strip. Journal of Civil engineering and Management, 15 (3), 269-280.

[15] PECDAR, (Palestinian Economy Council for Development \& Reconstruction). (2008). Infrastructure that needed for Palestinian trade. Retrieved from Jerusalem.

[16] Brghooth, G. (2013). Evaluation of infrastructure projects funded by international organizations in Gaza strip from partner's perspective from 2008 to 2012 (Master Thesis), Islamic University of Gaza, Gaza.

[17] Birzeit University, Development Studies Programme (2005). Human development report. Retrieved from Ramallah, Palestine. 
[18] Marcelo, D., Mandri-Perrott, C., House, S., \& Schwartz, J. (2015). Prioritization of infrastructure projects: A decision support framework. World, 1.

[19] Berechman, J., \& Paaswell, R. E. (2005). Evaluation, prioritization and selection of transportation investment projects in New York City. Transportation, 32 (3), 223-249.

[20] Burger, P., \& Hawkesworth, I. (2011). How to attain value for money: comparing PPP and traditional infrastructure public procurement. OECD Journal on Budgeting, 11 (1), 91.

[21] Sartori, D., Catalano, G., Genco, M., Pancotti, C., Sirtori, E., Vignetti, S., \& Del Bo, C. (2014). Guide to cost-benefit analysis of investment projects: Economic appraisal tool for cohesion policy 2014-2020. Evaluation Unit, DG Regional Policy, European Commission.

[22] Keng'ara, R. (2014). Effect of funds disbursement procedures on implementation of donor projects in Homabay County, Kenya. Universal Journal of Accounting and Finance, 2 (1), 923.

[23] Rathbone, M., \& Redrup, O. (2014). Developing infrastructure in Asia Pacific: Outlook, challenges and solutions. Singapore: Price waterhouse Coopers Services LLP.

[24] Roos, K., Wiener, D., Guldimann, R., \& Grossmann, M. (2014). Unleashing private capital investments for sustainable infrastructure greenfield projects. Basel, Switzerland: Global Infrastructure Basel Foundation.

[25] Runde, D. F., Savoy, C. M., Rice, C. F., Center for, S., \& International, S. (2016). Global infrastructure development: a strategic approach to U.S. leadership.
[26] World Bank (2014). Prioritizing Projects to Enhance Development Impact. Available from: http://www.worldbank.org [Accessed 25 january 2017].

[27] Liesiö, J., Mild, P., \& Salo, A. (2007). Preference programming for robust portfolio modeling and project selection. European Journal of Operational Research, 181 (3), 1488-1505.

[28] Nigim, K., Hipel, K., \& Smith, G. (2005). An effective approach to infrastructure reconstruction of devastated countries. Paper presented at the Proceedings of international symposium on the analytic hierarchy process.

[29] Lane, M. T. D., \& Bulir, M. A. (2002). Aid and fiscal management: International Monetary Fund.

[30] Jerve, A., \& Nissanke, M. (2008). Aid effectiveness to infrastructure: a comparative study of East Asia and subSaharan Africa: framework paper. JBICI Research paper, (361), 1-68.

[31] El-Sawalhi, N. and Mansour, M. (2014). Preparation critical success factors for Public Private Partnership (PPP) projects in Palestine. Journal of Engineering Research and Technology, 1 (2), 52-57.

[32] Wai, S., Yusof, A. M., Ismail, S., \& Ng, C. (2013). Exploring success factors of social infrastructure projects in malaysia. International Journal of Engineering Business Management, 5, 4. 